Discussion Paper No. 10-024

The Labour Share of Income:

Heterogeneous Causes for

Parallel Movements?

Jan Hogrefe and Marcus Kappler

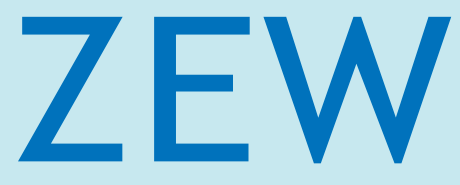

Zentrum für Europäische Wirtschaftsforschung $\mathrm{GmbH}$

Centre for European

Economic Research 
Discussion Paper No. 10-024

\title{
The Labour Share of Income: Heterogeneous Causes for Parallel Movements?
}

\author{
Jan Hogrefe and Marcus Kappler
}

Download this ZEW Discussion Paper from our ftp server:

ftp://ftp.zew.de/pub/zew-docs/dp/dp10024.pdf

Die Discussion Papers dienen einer möglichst schnellen Verbreitung von neueren Forschungsarbeiten des ZEW. Die Beiträge liegen in alleiniger Verantwortung der Autoren und stellen nicht notwendigerweise die Meinung des ZEW dar.

Discussion Papers are intended to make results of ZEW research promptly available to other economists in order to encourage discussion and suggestions for revisions. The authors are solely responsible for the contents which do not necessarily represent the opinion of the ZEW. 


\section{Non-technical summary}

Declining labour shares in a large number of countries, particularly in continental Europe, have renewed the academic and political debate about the factors which explain these downward trends. While the share accruing to labour in the division of national income was long being seen as constant over time, this stylised fact has recently been challenged. Several explanations for temporal and persistent movements of the labour share have been brought forward in the debate: effects of structural and technological change, influences of globalisation and increased product market integration, and the importance of institutional settings, often with a focus on wage bargaining structures.

The aim of this paper is to take a structured empirical approach at assessing the relative importance of those factors across countries. In particular, we focus on proper dynamic model specification and test the validity of the homogeneity assumption of slope coefficients frequently implied in previous studies. We employ fixed effect estimators as well as pooled mean group and mean group estimators, the latter two in a dynamic heterogeneous panel framework.

In a sample of OECD countries, we find negative effects for two explanatory variables of the labour share: the capital output ratio and trade openness. Furthermore, we are not able to reject the homogeneity assumption on the slope coefficients. This first finding lends important support to the standard theory on labour share movements. However, as far as other explanatory variables often found in the literature go, the picture is more mixed. Total factor productivity, in particular, is found to exert heterogeneous effects across countries and no clear support for the pooling assumption of slope coefficients in a linear dynamic model is found.

In order to add more detail to our analysis and to address the role of institutional arrangements, in particular with respect to the bargaining process, we split the sample into two groups of countries characterised by differently strong unions. We find important differences in the coefficient values and levels of significance. For more marketoriented countries with lower union density, we see the labour share being driven down by variables capturing technological change and shifts in the relative usage of factors of production. For countries with strong unions, however, we find trade openness to be the most relevant explanatory factor for downward movements of the labour share. We conclude this is due to trade openness reducing the possibilities of unionised employees to secure a wage markup in the distribution of factor incomes. 


\section{Das Wichtigste in Kürze}

Eine stetig fallende Arbeitseinkommensquote (AEQ), gerade in Kontinentaleuropa, hat das Interesse sowohl der Politik als auch der akademischen Forschung in dieses Maß makroökonomischer Verteilungsgrechtigkeit erneuert. Während die Forschung die AEQ lange als über die Zeit konstant angesehen hat, wird dieses makroökonomische "Faktum" immer mehr in Frage gestellt. Die Debatte hat in den letzten Jahren vielfältige Gründe für ein Absinken der AEQ zu Tage gefördert: Einflüsse des Strukturwandels und des technologischen Fortschritts, Globalisierungstendenzen und die institutionelle Struktur eines Landes - gerade mit Blick auf den Lohnverhandlungsprozess.

Ziel dieser Studie ist es, empirisch zu analysieren, welche Faktoren in welchen Ländern tatsächlich für die angesprochenen Trends verantwortlich sind. Im Detail richten wir den Fokus auf eine korrekte dynamische Spezifikation des Schätzmodells und darauf die Annahme der Gleichheit des Einflusses einzelner Faktoren zu testen, welche vielen Studien zum Thema innewohnt. Hierfür verwenden wir sogenannte "fixed effects", "pooled mean group" und "mean group" Schätzer. Letztere vereinen Heterogenität und Dynamik in einem Panel-Rahmen.

Für viele OECD Länder finden wir negative Effekte für zwei wichtige erklärende Variablen: Das Kapital-Output Verhältnis und die Handelsoffenheit eines Landes. Darüberhinaus können wir für diese Variable die Homogenitätsannahme nicht verwerfen. Dieses wichtige empirische Ergebnis liefert bedeutende Unterstützung für theoretische Ansätze zur Erklärung der AEQ. Andere, häufig in der Literatur verwendete Variablen, liefern ein weniger klares Bild. Gerade der Einfluss der totalen Faktorproduktivität scheint sehr heterogen über die Länder im Datensatz verteilt zu sein.

Um weitere Aussagen bezüglich der Wirkung institutioneller Rahmenbedingungen, insbesonere bezüglich des Lohnsetzungsprozesses, zu treffen, teilen wir unseren Datensatz in zwei Ländergruppen. Wir unterscheiden einerseits Länder mit starken und andererseits Länder mit schwächeren Gewerkschaften. Hieraus ergeben sich wichtige Unterschiede in der Wirkung einzelner Variablen. Für eher markt-orientierte Länder führen wir Veränderungen in der AEQ auf technologischen Wandel und Veränderungen im Faktoreinsatzverhältnis zurück. Für Länder, in denen Gewerkschaften eine starke Rolle einnehmen, zeigt sich die Handelsoffenheit als hauptverantwortlich. Hier scheinen die Gewerkschaften in einer globalisierten Welt weniger in der Lage, ihre Macht im Verteilungsprozess durchzusetzen. 


\title{
The Labour Share of Income: Heterogeneous Causes for Parallel Movements?*
}

\author{
Jan Hogrefe Marcus Kappler ${ }^{\dagger}$ \\ ZEW Mannheim ZEW Mannheim \\ hogrefe@zew.deｋappler@zew.de
}

April 28, 2010

\begin{abstract}
The aim of this paper is to take a structured approach at estimating the coefficients of factors explaining movements of the labour share across countries. In particular, we focus on proper dynamic specification and test the validity of the homogeneity assumption of slope coefficients frequently implied in previous studies. We employ fixed effect estimators as well as pooled mean group and mean group estimators, the latter in a dynamic heterogeneous panel framework.

We find support for a dynamic estimation setup and derive statements regarding the homogeneity assumption with respect to the three most prominent explanatory variables in the literature: the capital-output ratio, total factor productivity and trade openness. In addition, we take account of different institutional arrangements across countries.
\end{abstract}

JEL codes: C23, E23, E25, F16

Keywords: factor income, labour share, dynamic heterogeneous panel models

${ }^{*}$ The authors would like to thank Claudia Busl, Andreas Sachs, Simeon Vosen and participants at workshops and seminars in Berlin, Dresden and Mannheim for valuable comments and discussion. Maximilian Kohl provided excellent research assistance. All errors are, of course, our own.

${ }^{\dagger}$ corresponding author. Centre for European Economic Research (ZEW), P.O. Box 103443, D-68034 Mannheim, Germany. 


\section{Introduction}

The share accruing to labour in the division of national income is one of the classical topics of macroeconomics. However, it lay dormant for decades-assumed away in standard macroeconomic treatments as constant and straightforwardly derived from a Cobb-Douglas production function. This constancy of the labour share has recently been challenged and with it one of the stylized facts in macroeconomics. Declining labour shares in a large number of countries, particularly in continental Europe, have brought the topic back onto the political agenda - often accompanied by passionate discussions about implied inequality concerns. To put it shortly: It seems as if the labour share is making an impressive comeback. ${ }^{1}$

Figure 1 clearly shows the source of concern: For a sample of OECD countries, the labour share has on average declined by roughly seven percentage points since 1980 . For individual countries the picture is similar. All countries in the sample individually report a decline except for the United States where the labour share has nearly remained constant. $^{2}$

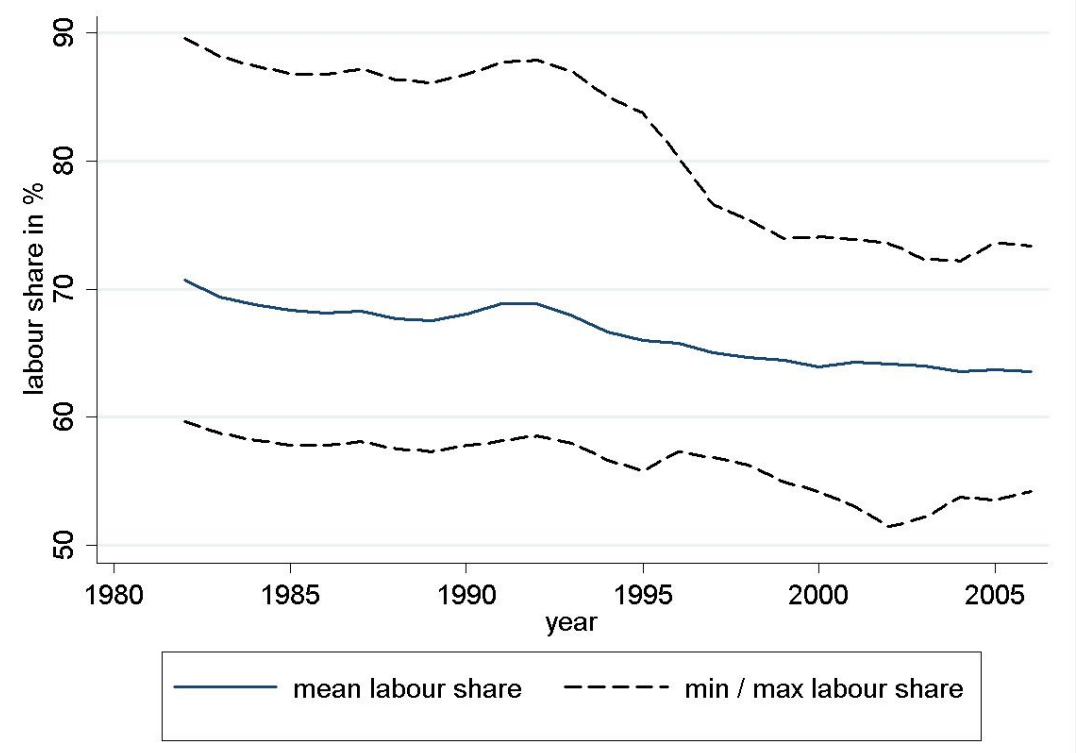

Figure 1: The average labour share in a sample of OECD countries

\footnotetext{
${ }^{1}$ See Atkinson (2009) and the references therein for a re-appraisal.

${ }^{2}$ See section 4 for descriptive statistics, details on the sample and the computation of variables.
} 
In the face of labour shares declining almost in parallel across a vast majority of developed countries, several recent studies try uncovering the underlying forces and possible implications. The strands of arguments may roughly be grouped into the following segments: effects of structural and technological change, influences of globalisation and increased product market integration, and the importance of institutional settings, often with a focus on wage bargaining structures.

The effects of changes in relative factor inputs in production and technological change are most prominently discussed in Bentolila and Saint-Paul (2003). They show that the impact of changes in relative factor inputs and factor prices can be comprehensively modelled via the capital output ratio. The direction of the impact on the labour share then depends on the elasticity of substitution between labour and capital. With the two factors being substitutes, the labour share declines with an increase in the capital output ratio. As far as technological change is concerned, they show that only capital augmenting technological change has the potential to shift the capital output schedule and create long-term downward pressure on the labour share. A recent contribution by Arpaia et al. (2009) extends this model to incorporate different skill categories of labour to highlight the important issue of capital-skill complementarity.

In recent work, globalisation took center stage as the most likely candidate among many explanatory factors in the analysis of declining labour shares all over continental Europe and beyond. Numerous studies have analysed the effects of greater trade integration on factor shares. In general, it is argued that greater trade openness exerts downward pressure on the labour share either through Stolper-Samuelson-type relative factor price effects or via power-shifts in the wage bargaining process. In the latter case it is assumed that in more open economies the firm's outside option improves relative to that of employees if costs of relocating production or sourcing goods from spatially differentiated locations are less than prohibitively high. Furthermore, stiffer international competition can decrease mark-ups of firms, raising labour shares. An early study by Harrison (2002) shows negative effects of increasing trade openness and occurences of exchange rate crises for a large sample of developing and developed countries. Jaumotte and Tytell (2007) add further measures of globalisation including immigration and also establish a negative link. However, the effect of increased trade openness also features a certain degree of heterogeneity with respect to time, regional aspects and measurement. 
Guscina (2006) stresses that the effect is significant in the most recent two and a half decades only; Buch et al. (2008) show that Italian regions are differently affected than German ones; and Hutchinson and Persyn (2009) develop more sophisticated measures of trade openness that render the effect insignificant.

Besides globalisation, labour market institutions are frequently brought up as explanatory factors in the quest for uncovering the mechanisms of factor share dynamics. Checchi and Garcia-Peñalosa (2008) point to potentially heterogeneous effects of institutions on the labour share and stress the importance of empirically determining the direction of the overall effect. Blanchard and Giavazzi (2003) emphasize the intertemporal aspect of such institutions. They propose that in the short run institutions which increase the bargaining power of workers could lift the labour share, while the same institutions could set the labour share off on a declining track when employers substitute capital for relatively more expensive labour in the long-run. Most studies with a focus on globalisation also integrate into the analysis aspects of labour market institutions.

We contribute to the inspiring research outlined above and by stressing two points: dynamics and cross-country heterogeneity in estimated slope coefficients. The first point has so far mostly been addressed in a rather ad-hoc manner by simply including the dependent variable as a one period-lag. Yet, as Pesaran and Smith (1995) have shown, there is considerable danger in blind trust in pooled dynamic models. In such models, severely biased estimates could be the results of data best described by heterogeneous slope-coefficients across sample units, i.e. if the effects of certain variables differ across countries in our case. Therefore we apply estimators which allow us to directly test the homogeneity assumption of all slope-coefficients inherent in most previous studies. Assessing heterogeneity furthermore enables us to retrieve country specific insights into the driving forces of movements in the labour share.

The idea of possibly heterogeneous slope coefficients is clearly valid; each of the most prominent explanatory variables in studies on the labour share gives at least some reason to doubt a uniform impact mechanism across countries. As stated above, this also implies worries about potentially biased results in dynamic estimations.

The impact of the capital-output ratio has been shown by Bentolila and Saint-Paul (2003) to be sector-dependent - crucially influenced by the sector's elasticity of substitution between production factors. This in turn implies that different sectoral compositions 
of the economies in the sample could potentially introduce heterogeneity across countries as well. However, the distribution of value added and employment across sectors is fairly similar for the countries in our sample. This might limit the scope for heterogeneous coefficients in this case.

The impact of Total Factor Productivity $(T F P)$ developments across countries may also differ. This variable is mostly included in order to capture the nature of technological change. This makes TFP a more or less suitable variable on a country-by-country basis given the true nature of technological change may be different across countries.

Reason to doubt the cross-country homogeneity of the influence globalisation exerts on the labour share particularly comes from the complex interaction of trade openness and the production and employment structure in the respective countries. In addition, if one assumes that increased openness puts labour at a general disadvantage in the wage bargaining process, the country-specific institutional arrangements matter as well. Note that for all these cases, should heterogeneity be indeed important, fixed effect methods provide insufficient controls, since they merely account for the time-constant elements of country specific characteristics and capture heterogeneity through differing intercepts only.

However, it is not clear whether and to what degree this heterogeneity is indeed important. It might not bias the results after all. For now, we merely state the possibility and take it seriously in the estimation below. This is, we rely on technical methods to check the validity of the pooling assumption implied in most econometric treatments the literature offers. We test a basic model of the labour share consisting of the main explanatory variables that surfaced in the literature. Yet, we do not restrict the influence of those factors to be homogeneous across countries. We estimate the driving forces of labour share fluctuations in a dynamic heterogeneous panel framework. Particularly, we employ the pooled mean group (PMG) estimator and the mean group (MG) estimator as in Pesaran et al. (1999) and Pesaran and Smith (1995), respectively. The PMG estimator represents a dynamic pooled model with a homogeneity restriction on all long-run coefficients, which are in the focus of our analysis. The MG estimator explicitly allows for slope-heterogeneity in those long-run coefficients in contrast to mere intercept or short-run heterogeneity. Therefore, it provides the basis for direct tests on the validity of the pooling assumption which we carefully discuss. More generally, our estimates serve 
as a robustness check of the results previously brought forward in the literature, since we also employ standard fixed-effects estimators and compare the results to our preferred specifications.

Note that our aim is not to participate in the quest for further possible explanatory variables, but to take a structured approach at assessing the relevance and importance of those factors that can be seen as fairly established in the literature. We believe that a thorough treatment of dynamics and possible country specific impacts could shed further light on the development of the labour share.

This paper is organised as follows: The section following this introduction briefly outlines the theoretical framework and clarifies the predicted impacts of our explanatory variables. In section 3 the theoretical model is transformed into an estimation setup and the empirical strategy is explained. The estimators are introduced and their suitability and particular use are carefully discussed. Section 4 reports sources and computations of the data while section 5 presents the results of our econometric exercises. A final section concludes.

\section{Theoretical background}

The goal of this section is to motivate, in a way consistent with theory, the explanatory variables that are assumed to affect the labour share $(L S)$. We mostly build on Bentolila and Saint-Paul (2003). They show that movements in the labour share can in general be explained in terms of three different channels. First they show the capital output ratio $k=K / Y$ to, under certain assumptions, comprehensively explain movements of the labour share triggered by effects such as changes in wages or factor shares in production. Secondly, they show that certain departures from the original assumptions can shift this relationship. Thirdly, they provide guiding theory for cases in which the economy is put off the schedule defined by the relationship between $k$ and $L S$. We follow their theoretical insights and briefly introduce each case.

The capital output ratio as a simple but comprehensive determinant of fluctuations of the labour share emerges irrespective of a strict functional form. As long as firms produce under constant returns to scale, labour and capital are the sole inputs, labour markets are perfectly competitive and technological progress is not capital augmenting, 
the labour share can be expressed as a function of $k, L S=g(k)$. This encompasses all changes in wages, interest rates, factor inputs or labour augmenting technological change as long as the above assumptions are maintained. The direction of the effects on the labour share then depends on the elasticity of substitution. It can be shown, that a higher $k$ only lowers the labour share if the factors are substitutes, i.e. $\delta L S / \delta k<0$ only if the elasticity of substitution is greater than one.

If the assumption on the nature of technological progress is lifted and capital augmenting technological change is allowed for, changes in $k$ are no longer a sufficient explanation for labour share movements. Bentolila and Saint-Paul (2003) show that capital augmenting technological change shifts the curve described by $g(k)$ in a multiplicative way. This means that the original relationship is preserved and a change in factor prices or inputs moves the labour share following the same mechanism as above, but it does so at a different level of $L S$ which is determined by the size of the factor bias inherent in capital augmenting technological change. At this point it is enough to note that now $L S=g(k, A)$ with $A$ representing capital augmenting technological change.

A second possibility for deviations from the original, purely $k$-based, relationship are non-competitive features in the product or labour market. If factors are not paid their marginal product, the economy moves off the schedule derived under the strict set of assumptions above. Consider for example a situation in which bargaining takes place over wages and assume that the process can be modeled in an efficient bargaining context. Then, the labour share is affected by the relative bargaining power of employers and employees. Following the literature, we consider trade openness an important indicator of relative bargaining power. If trade openness is a valid approximation for an economy's integration into world markets and its cost of access to the latter, the value of the outside option of firms in the bargaining process increases with openness. Thus, the labour share is negatively affected. It is interesting to note, that trade openness can affect the labour share in numerous ways. If trade triggers Stolper-Samuelson-type effects, those should be captured by the $g(k)$ schedule, since they imply simple changes in factor inputs and prices. Trade openness could also act as competition enhancing, driving down mark-ups of firms via reducing their market power. For now, we consider the impact and sign of the coefficient of trade openness an empirical issue and postpone further details to later sections. At this point we simply state a general relationship for the labour share 
as $L S=g(k, A) h(X)$ with $\mathrm{X}$ standing for all possible "shift factors" driving a wedge between the marginal product of labour and the real wage. We assume $h($.$) to have an$ exponential form.

In the estimations detailed in section 5 , we allow for all the above cases by including the variables most commonly used in the literature. We directly control for the capital output ratio and allow for the possibility of capital augmenting technological change by including an index of Total Factor Productivity. An important test will be to compare the signs of the estimated coefficients on $k$ and TFP. Only with the coefficients for $k$ and TFP being equally signed one can infer that technological change is indeed capital augmenting. When assessing the impact of $k, T F P$ and trade openness on the labour share, we also allow for different institutional arrangements across countries.

Figure 2 summarises this section in a graphical framework based on Bentolila and Saint-Paul (2003).

Figure 2: Theoretical influence on the labour share

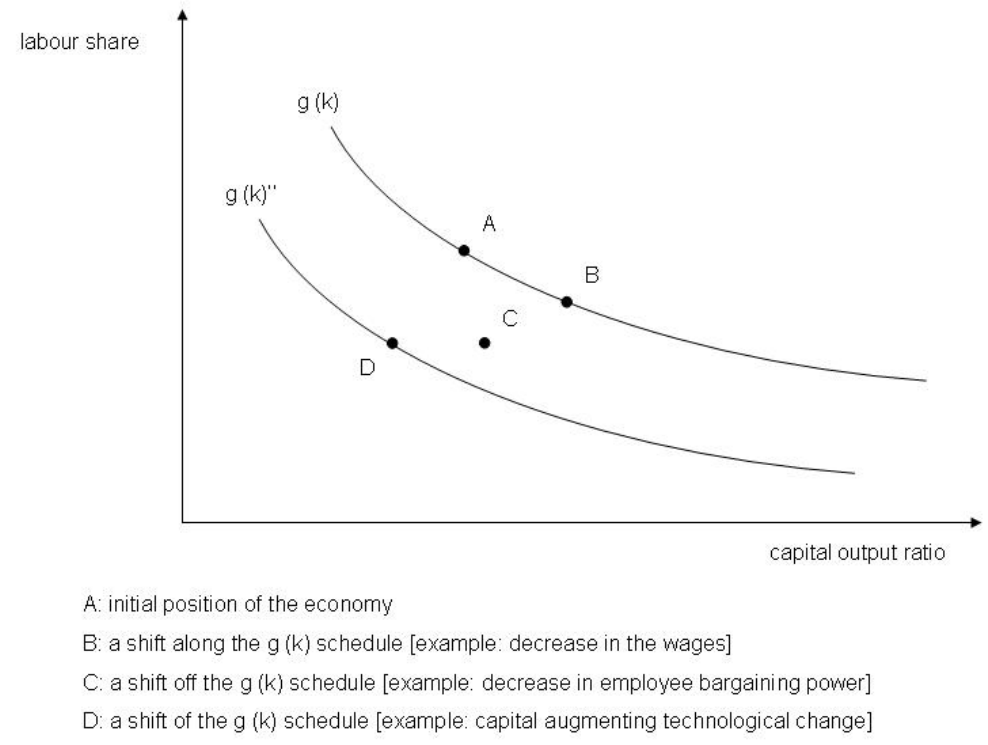




\section{Empirical Framework}

The aim of the remaining sections is to test the explanatory power of the outlined theory. To this end, we have to chose suitable estimators among the many that panel econometrics, in particular for macro panel data, offer. Two principles guide us through this selection process. The first principle is that we take serious account of cross-sectional heterogeneity in the data, i.e. we carefully deal with the question whether to employ pooled or country-specific estimators in order to receive reliable empirical results. The second principle is the preference of estimators based on dynamic rather than static models since our objective is not only to explain cross-country differences in the labour shares but also to gauge the persistence in the evolution over time.

Obeying to the second principle is straightforward by considering an autoregressive distributed lag (ARDL)-Model as in Pesaran et al. (1999)

$$
y_{i t}=\sum_{j=1}^{p} \lambda_{i j} y_{i t-j}+\sum_{j=0}^{q} \delta_{i j}^{\prime} \mathbf{x}_{\mathbf{i t}-\mathbf{j}}+\mu_{i}+\epsilon_{i t}
$$

in which $y_{i t}$ represents country $i$ 's observation on the logarithm of the labour share in period $t$ and $\mathbf{x}_{\mathbf{i t}-\mathbf{j}}$ is the vector of the explanatory variables. Slope coefficients to be estimated are given by $\lambda_{i j}$ and $\delta_{i j}^{\prime}$ and $\mu_{i}$ is a time-invariant fixed effect. The indices run from $t=1, \ldots T$ and $i=1, \ldots N$.

By reparameterisation the following error-correction representation of (1) emerges

$$
\Delta y_{i t}=-\phi_{i} y_{i t-1}-\beta_{i}^{\prime} \mathbf{x}_{i t}+\sum_{j=1}^{p-1} \lambda_{i j}^{*} \Delta y_{i t-j}+\sum_{j=0}^{q-1} \delta_{i j}^{*^{\prime}} \Delta x_{i t-j}+\mu_{i}+\epsilon_{i t}
$$

where $\phi_{i}=\left(1-\sum_{j=1}^{p} \lambda_{i j}\right), \beta_{i}=\sum_{j=0}^{q} \delta_{i j}, \lambda_{i j}^{*}=-\sum_{m=j+1}^{p} \lambda_{i m}, j=1, \ldots, p-1$ and $\delta_{i j}^{*}=-\sum_{m=j+1}^{q} \delta_{i m}, j=1, \ldots, q-1$.

These two equations suffice for organising ideas and for demonstrating the parameter restrictions inherent to the estimators we look at.

\subsection{Consistency versus efficiency}

To begin with, we consider the static fixed effects (FE) estimator which is still the model of choice in many empirical studies, in particular the ones that seek to estimate 
the determinants of the labour share. In terms of our model, the FE estimator imposes the following parameter restrictions

$$
\begin{aligned}
\lambda_{i j} & =0 \quad \forall i, j \\
\delta_{i j}^{\prime} & =0 \quad \forall j>1 \text { and } \forall i \\
\delta_{i 1} & =\delta_{1} \quad \forall i
\end{aligned}
$$

and it is evident that such a model may easily be rejected by the data: it implies no delayed effects from the endogenous and explanatory variables and the only source of cross-country heterogeneity is attributed to the country fixed-effect $\mu_{i}$. The FE estimator, however, is adequate if the long-run response of the labour share is indeed best captured by the cross-country variation in the data and if dynamic effects are negligible.

Contrary to this, if heterogeneity between countries dominates then the data is more appropriately explained by a set of country-by-country regressions. In this case, the overall effect in the panel may be summarised by computing the Mean Group (MG) estimator of Pesaran and Smith (1995). The MG estimator is the simple average of the country-specific slope estimates and proven to be a consistent parameter estimator if slope coefficients are heterogeneous and $N$ and $T$ are sufficiently large. Since the interest is on the long-run effects, the MG estimator computes $\theta^{M G}=\frac{1}{N} \sum_{i=1}^{N} \frac{-\hat{\beta}_{i}}{\hat{\phi}_{i}}$, where we obtain $\hat{\beta}_{i}$ and $\hat{\phi}_{i}$ from $N$ individual unrestricted regressions of equation (2).

An alternative procedure that brings a balance between the strongly restricted FE estimator and the fully heterogeneous MG estimator is given by the Pooled Mean Group (PMG) framework of Pesaran et al. (1999). Taking equation (2) as reference, the PMG estimator imposes the following homogeneity restrictions

$$
\beta_{i}=\beta \quad \forall i .
$$

The PMG estimator restricts the long-run parameters to be the same across countries but leaves the parameters concerning the error correction coefficients $\phi_{i}$ and the coefficients of the short-run dynamics unrestricted. The set of long-run parameters that maximises the concentrated likelihood function belonging to the panel data model gives the PMG estimator $\beta^{P M G}$. 
If homogeneity of the $\beta$-parameters holds, then the PMG estimator is consistent and efficient, whereas the MG estimator is only consistent. Likewise, if the model is homogeneous and dynamic responses are absent, then the FE estimator is preferable in terms of efficiency. Principally, in choosing among the FE, MG and PMG estimators we face a trade-off between consistency and efficiency. From the outset it is not clear which estimator accurately measures the relationships between the labour share and its determinants. Theory suggests that there might be both heterogenous and homogeneous causes for the parallel movement in the labour shares, but in order to clarify which explanatory variable exerts what effect, we employ Hausman specification tests to check whether homogeneous or heterogeneous parameter estimates are consistent with the observered data.

\subsection{Cross-sectional dependence}

So far we have been silent on the assumptions about the error terms $\epsilon_{i t}$ in equation (1) and (2). The standard FE, MG and PMG estimation framework assumes that the disturbances $\epsilon_{i t}$ are independently distributed across $i$ and $t$. A more reasonable assumption is that countries are cross-correlated due to international linkages and common influences such as common macroeconomic shocks. Neglecting such dependencies yields inefficient parameter estimates and is likely to lead to size distortions of conventional tests of significance. A convenient way to incorporate cross-sectional dependence in our framework is to model such dependencies by a factor error structure. Under this assumption, the errors of equation (2) are given by

$$
\epsilon_{i t}=\gamma_{i} f_{t}+e_{i t}
$$

in which $f_{t}$ is a unobserved common effect and $e_{i t}$ are independently distributed country-specific errors. Such an empirical specification seems to be more in line with a model of the labour share featuring technological change as an important determining variable that may comprise common components across countries.

Pesaran (2006) shows that, in principle, directly augmenting the panel model with a set of cross-sectional averages of all variables can capture the correlated error component. However, considering the large time series dimension of such an approach, following 
Binder and Bröck (2006) we pursue a more parsimonious specification which results in conducting a two-step procedure when estimating equation (8). The basic insight that lies behind the common correlated effects estimator developed in Pesaran (2006) is that a proxy for the unobserved common factor can be obtained as

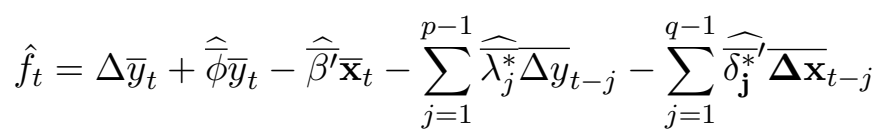

in which bar variables denote cross-sectional averages à la $\bullet_{t}=\sum_{i=1}^{N} \bullet_{i t}$ and hatted coefficients are from a first step estimation of

$$
\Delta \bar{y}_{t}=-\bar{\phi} \bar{y}_{t}-\bar{\beta}^{\prime} \overline{\mathbf{x}}_{t}+\sum_{j=1}^{p-1} \bar{\lambda}_{j}^{*} \Delta y_{t-j}+\sum_{j=1}^{q-1}{\overline{\delta_{\mathbf{j}}^{*}}}^{\prime} \overline{\boldsymbol{\Delta x}}_{t-j}+\varepsilon_{t}
$$

In a second step, we replace $f_{t}$ from (7) with $\hat{f}_{t}$ from (8) and estimate the errorcorrection model as shown by equation (2) with the help of this factor estimate.

\section{Data}

This section describes the data and provides details on the calculations of all variables used in the next section's estimations. The labour share of income is one of the most classical measures in macroeconomics, yet, it is not uniquely defined. We use data provided in the "total economy database" (TED) where the labour share is defined as total labour compensation (LAB) divided by gross value added (VA): $L S_{i t}=L A B_{i t} / V A_{i t} .^{3}$ It is important to note that labour compensation contains an imputed labour income of the self-employed, thereby providing a better cross-country comparability as stressed by Gollin (2002).

The capital output ratio $k$ is calculated with capital stock data from the EU's Ameco database as the net capital stock in year $t$ over GDP in the same year. ${ }^{4}$ Total factor productivity $(t f p)$ data is also taken from TED. Trade openness is calculated as the sum of imports and exports divided by GDP with data from the OECD Economic Outlook database. In order to capture different institutional settings, in particular with respect

\footnotetext{
${ }^{3}$ This database is available at $h t t p: / / w w w . g g d c . n e t /$ databases/ted.htm

${ }^{4}$ This database is available at http://ec.europa.eu/economy_finance/db_indicators/db_indicators8646_en.htm. Data for Germany prior to 1991 are calculated based on capital stock growth rates for West Germany.
} 
to the bargaining process, we characterize countries as either having strong unions or weak ones using union density as the principal measures. These data are provided by and described in Visser (2009). All data are at yearly frequency. Table 1 shows summary statistics for our resulting balanced sample of 15 OECD countries over 25 years (1982 2006).

The descriptive statistics again clarify the downward movement of labour shares across almost every country in the sample, with the United States being the only exception. At the same time countries have become more open and experienced substantial increases in Total Factor Productivity. The assessment is less clear with regard to the capital output ratio, which has increased for some and decreased for others. In addition, union density is now lower than in the 1980s for all countries except Belgium and Finland.

While the descriptive statistics point to some interesting relationships between variables, it remains for the next section to establish significant links between the labour share and its driving forces. 


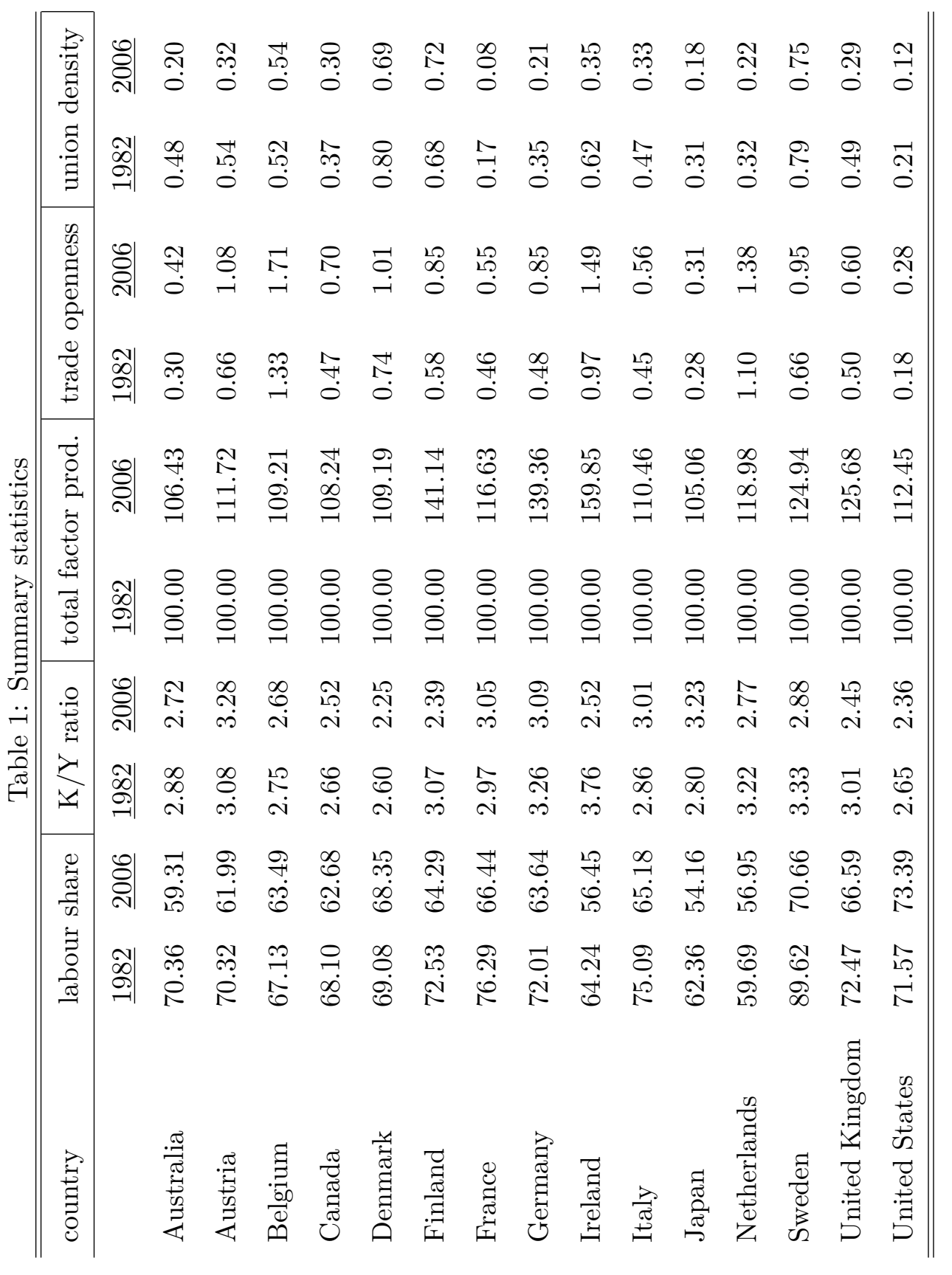




\section{Results}

With the empirical strategy in place, we can proceed to describing the results and their interpretations in this section. Table 2 shows alternative estimates of the ARDL model of the labour share. The short-run dynamics of the PMG and MG models have been specified with the aid of the Akaike information criterium where we allowed for a maximum lag of order one.

For the $\log$ of the capital output ratio $\ln (k)=\ln (K / Y)$ the coefficient is negative for all three estimated models - FE, PMG and MG. However, a large (heteroscedasticitycorrected) standard error renders the FE estimator insignificant. According to theory, the negative coefficient sign hints to an average economy-wide elasticity of substitution larger than one, pointing to labour and capital being substitutes. The PMG and MG estimates are also in line with other estimates in the literature as, for example, in Hutchinson and Persyn (2009) or Bentolila and Saint-Paul (2003). More importantly, the MG estimate seems broadly in line with its pooled counterparts, suggesting the validity of the pooling assumption in this case - a point emphasised by a Hausman test, which takes the value of .94 and therefore does not reject the homogeneity of coefficients across the PMG and MG specifications according to the critical value of the $\chi^{2}(1)$ distribution. A similar picture emerges with regard to Total Factor Productivity. Estimated coefficients are negative. Theory tells us that equally signed coefficients for $\ln (k)$ and $\ln (T F P)$ reveal technological progress to be capital augmenting (Bentolila and Saint-Paul (2003)). Given that the MG turns out to be insignificant, the homogeneity assumption of the $\ln (T F P)$ coefficient is questionable. We pointed out above that technological developments in the OECD countries are very similar. However, technological change seems to influence the labour share quite heterogeneously across countries. This can be seen clearly in figure 5 were country-specific deviations from the MG coefficient estimates are shown. The individual slope estimates for the $\ln (T F P)$ variable scatter quite a lot around the $\mathrm{MG}$ estimate. For several countries the $\ln (T F P)$ coefficient is even positive which suggests that - given the negative sign of the capital/output coefficient - technological progress is neither labour- nor capital augmenting (Australia, Austria, Ireland and the US). Individual slope estimates of the trade openness variable also fluctuate around the MG counterpart but to a lesser extent. However, we cannot reject the homogeneity assump- 
Table 2: Estimates based on the full country-sample

\begin{tabular}{llll}
\hline \hline & $\mathrm{FE}$ & $\mathrm{PMG}$ & $\mathrm{MG}$ \\
\hline $\ln (k)$ & -0.169 & $-0.305^{* * *}$ & $-0.299^{* * *}$ \\
& $(0.106)$ & $(0.055)$ & $(0.093)$ \\
$\ln ($ TFP $)$ & $-0.448^{* * *}$ & $-0.435^{* * *}$ & -0.257 \\
& $(0.123)$ & $(0.059)$ & $(0.153)$ \\
Trade Openness & $-0.097^{* *}$ & $-0.110^{* * *}$ & $-0.160^{*}$ \\
& $(0.041)$ & $(0.022)$ & $(0.086)$ \\
\hline \hline
\end{tabular}

$\overline{\overline{\text { Notes: }}{ }^{* * *} /{ }^{* *} /{ }^{*} \text { denotes significance to the } 1 \% / 5 \% / 10 \% \text { level, respectively, according }}$ to the two-sided critical values of the Student's t distribution. Figures in brackets are the standard errors which are corrected for possible heteroscedasticity in the case of the FE estimates.

tion on the estimated coefficients based on Hausman tests. Returning to table 2, we find trade openness to negatively and significantly affect the labour share in all three specifications.

We furthermore note that a dynamic specification is preferable over a static one given that for all country specific models at least two of the variables are significant in contemporaneous values as well as when included with one lag. There is not a single country for which the labour share is best described by a static model.

While our results from table 2 establish a decent benchmark, they leave out one important aspect that features in nearly all papers on the topic: institutional arrangements, in particular with relevance for the wage bargaining process. Therefore, we comply with other studies and test whether institutional settings influence our estimates. However, we proceed in a different fashion with respect to the precise way of accounting for institutions. We do not directly include institutional variables in the estimation but divide the sample and test for the stability of the other variable's coefficients in the split samples. Note that an approach using the full sample and an interaction term is not feasable when employing the MG estimator. Directly including measures for the relative strength in the bargaining process is not an option either; this is for the following reasons: (i) we need a sufficient amount of variation in the variables over time; (ii) our time series based estimation approach does not allow to estimate models with many variables; and (iii) 

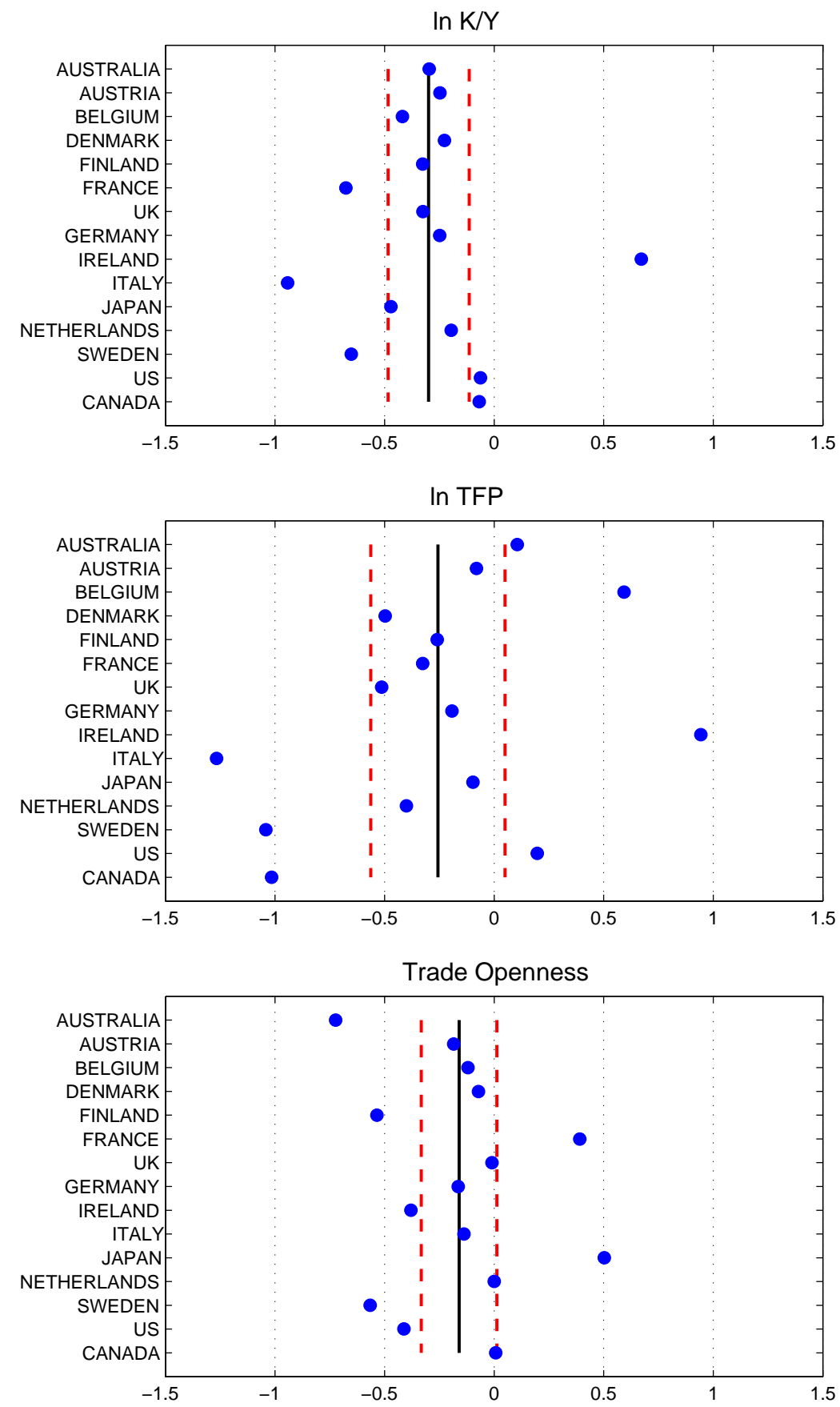

Notes: Dots show the individual estimates of the long-run coefficients. The solid line indicates the MG estimate. Dotted lines denote MG estimates +/- 2-times the standard error.

Figure 3: Individual vs. MG estimates 
Table 3: Country groupings

\begin{tabular}{c|c}
\hline \hline High union density & Austria, Belgium, Denmark, Finland, Ireland, Italy, Sweden \\
Low union density & Australia, France, UK, Germany, Japan, Netherlands, US, Canada \\
\hline \hline
\end{tabular}

institutional proxies are typically plagued by measurement error, which would result in biased point estimates.

In the following, we divide our sample into two country groups according to whether they can be described as having high or low union density and redo the estimations. Union density tells us the percentage of the workforce that is member of a union. We define countries that fall into the high union density group if their average value is above the cross-sectional median over the period from 1982 to 2006 . Table 3 shows the country groupings based on this classification scheme.

One point deserves further discussion. Researchers often face a choice between various measures for the unionisation of a country. In particular a choice between union density and union coverage. The latter gives the share of employees covered by wage agreements and paid accordingly - irrespective of direct union membership. While it is generally difficult to decide in favour of either union density or union coverage to be included in a model, we prefer union density in our setup. We believe union density has stronger implications for the bargaining power of employees. For a union's clout in labour conflicts it is of crucial importance how many actual members it has since this directly determines the finances available through membership fees and the manpower in strikes and lockouts. ${ }^{5}$

A general and not surprising result emerging from table 3 is that the Anglo-Saxon countries are characterised by low unionisation relative to the sample median and that the Continental European, in particular the Scandinavian countries have relatively strong union membership shares in total employment. Thus, the following "sample split" exercise can, with some exceptions, also be seen as a crude comparison of differences in labour share influences between the English speaking world and Continental Europe.

Turning to the results if we split the sample according to union density (table 4) we

\footnotetext{
${ }^{5}$ Using union coverage to divide the two groups yield a largely similar grouping.
} 
Table 4: Estimates based on union density country groupings

\begin{tabular}{lccc|ccc}
\hline \hline & \multicolumn{3}{c|}{ High union density } & \multicolumn{3}{c}{ Low union density } \\
& FE & PMG & MG & FE & PMG & MG \\
\hline $\ln (k)$ & -0.194 & $-0.756^{* * *}$ & -0.268 & $-0.221^{*}$ & $-0.370^{* * *}$ & $-0.391^{* * *}$ \\
& $(0.143)$ & $(0.115)$ & $(0.196)$ & $(0.125)$ & $(0.079)$ & $(0.123)$ \\
$\ln (T F P)$ & $-0.516^{* * *}$ & $-0.795^{* * *}$ & -0.175 & $-0.395^{* * *}$ & $-0.536^{* * *}$ & $-0.500^{* * *}$ \\
& $(0.178)$ & $(0.095)$ & $(0.305)$ & $(0.135)$ & $(0.079)$ & $(0.147)$ \\
\multirow{3}{*}{ Trade Openness } & $-0.095^{*}$ & $-0.278^{* * *}$ & $-0.287^{* * *}$ & $-0.063^{* *}$ & -0.007 & -0.018 \\
& $(0.055)$ & $(0.055)$ & $(0.087)$ & $(0.031)$ & $(0.036)$ & $(0.096)$ \\
\hline \hline
\end{tabular}

find that poolability of slope coefficients for the capital/output $(\ln (k))$ and the $\ln (T F P)$ variable seems not warranted for the countries that are classified as having high union density. Pooled Mean Group estimates of both slope coefficients are significant, but insignificant Mean Group estimates point to large cross-country variations in those estimates. In contrast, all three estimates for the trade openness coefficient turn out to be significantly negative. Furthermore, a Hausman test does not reject the null hypothesis of poolability for this latter variable. In comparison to the full sample estimates, the MPG and MG estimates of trade openness are approximately twice as high in absolute value.

Findings for the low union density countries show some interesting differences. First, FE, PMG and MG estimates for $\ln (k)$ and $\ln (T F P)$ are negative and significant. PMG and MG estimates are similar and a Hausman test does not reject poolabilty of the $\ln (k)$ and $\ln (T F P)$ coefficients. Secondly, trade openness does not seem to influence the labor share in the low union density countries since both the PMG and MG coefficients are not significantly different from zero. This casts doubt on the negative and significant static FE estimate.

It is important to discuss the results reported in table 4 in comparison to our findings for the full sample estimates. Remember that we do not reject the poolability hypothesis for $\ln (k)$ based on the full sample estimates shown in table 2 , but we do reject the same hypothesis for the high union density countries. Similarly, we find poolable coefficients 
for trade openness in the full sample, but not in the low union density country group. This discrepancy can be explained twofold: on a more technical point it must be noted that the MG estimator is particularly vulnerable to outliers as it simply computes the average of the country-specific slope estimates. Consequently, its precision increases with $N$, the cross-sectional dimension. Given that our sample split estimates are based on rather small subgroups, insignificant MG estimates may simply reflect small sample problems of the MG approach which in turn leads to a rejection of the poolability hypothesis. A second explanation brings us back to one of our main concerns, namely the treatment of cross-sectional heterogeneity. The question whether to pool or not to pool is naturally linked to the sample under consideration. If we allow for more homogeneity within a given sample as we do when countries are pre-grouped by a certain homogeneity criterion (union density), we would regard tests on the poolability of parameters as more powerful than in a sample with relatively heterogeneous countries. In this respect, the findings on poolability and non-poolability of parameters in the split sample may be preferred over those from the relatively heterogeneous full sample.

The upshots of the analysis that takes the influence of wage bargaining institutions into account are the following: First, for the countries with low unionisation (or low institutional bargaining power of employees) we find a high degree of homogeneity with respect to influences on the labour share through the capital output ratio and technological progress. Furthermore, the trade channel seems to have no role in affecting the relative compensation of employees in these countries. Secondly, for the countries that are classified as having powerful employees in the bargaining process, the picture is more mixed. However, there is more evidence that the trade channel is more important and may exert more downward pressure on the labour share than in countries with less influential employee institutions.

To bring theory and the empirical findings together, recall our above considerations with respect to how trade affects the labour share. We argued that the trade channel not picked up elsewhere is the possible power shift in the wage bargaining process. Now assume that any given change in trade openness might exert a heterogeneous effect across countries if there are different institutional arrangements. Our results point to stronger negative trade effects in countries with relatively many union members. A possible explanation for that finding may be the following. In countries where the bargaining 
power of employees is already low, or the wage setting process is simply not characterised by bargaining but by market forces instead, employees do not suffer a loss in relative compensation when the bargaining power of the employer increases, for instance due to an increase in a firm's outside option. Put simply, if there is no union wage markup, the labour share is not vulnerable to shifts in relative bargaining power. In countries where the labour share was held at a higher level through strong unions, international cost competition and easier access of firms to the world's labour supply brought down the labour share.

For the sample characterised by low union density, we also find the impact of the capital output ratio and the Total Factor Productivity to be poolable and to exert negative and visible influences. This may well hint at a stronger influence of technological change in those countries. Adjustments in relatives shares of factors used in production could be swifter and the effect of capital-augmenting technological change is visible in the labour share's development. In the other countries, an organised workforce might better be able to shield itself from the forces of technological change. Yet, as argued above, globalisation makes this an ever more difficult task.

The above results emphasize the virtues of caution in the interpretation of the driving forces of the labour share. Even if one cannot technically reject the pooling assumption for empirical models of the labour share, this does not rule out important differences in the effects across countries or groups of countries.

\section{Conclusion}

The initial motivation for this paper was to shed some light on the key driving forces underlying the downward movement in labour shares across a variety of countries. More precisely, it was about assessing whether the explanatory variables exert the same influences in all countries; we wanted to test the pooling assumption on slope-homogeneity implied by almost all existing studies on the topic. For this purpose, we estimated the determinants of labour share movements with standard fixed effects models as well as in a dynamic heterogeneous panel framework. The latter allowed us to employ estimators which differ in their assumptions on slope-homogeneity and to subsequently compare the results. Based on those PMG and MG estimators we find the pooling assumption 
to be valid for two variables - the capital output ratio and trade openness. This first finding lends important support to the theory on labour share movements along the lines of Bentolila and Saint-Paul (2003). However, as far as other explanatory variables often found in the literature go, the picture is more mixed. Total Factor Productivity, in particular, is found to have heterogeneous slope coefficients across countries and no clear support for the pooling assumption is found.

In order to add more detail to our analysis and to address the role of institutional arrangements, we test for possible clusters among countries characterised by differently strong unions from which we assume implications for the wage bargaining process. We find important differences in the coeffcient values and levels of significance. For more market-oriented countries with lower union density, we see the labour share being driven by variables capturing technological change and shifts in the relative usage of factors of production. For countries with strong unions, however, we find trade openness to be the most relevant explanatory factor for downward movements of the labour share. We conclude this is due to trade openness reducing the possibilities of unionised employees to secure a wage markup in the distribution of factor incomes.

Given the above results, we conclude that further research as well as scientific policy advise should take possible slope-heterogeneity and institutional arrangements into account when estimating models describing the labour share.

\section{References}

Arpaia, A., Pérez, E., and Pichelmann, K. (2009). Understanding labour income share dynamics in Europe. European Commission Economic Papers, (397).

Atkinson, A. (2009). Factor shares: the principal problem of political economy? Oxford Review of Economic Policy, 25(1):3-16.

Bentolila, S. and Saint-Paul, G. (2003). Explaining movements in the labor share. Contributions to Macroeconomics, 3(1).

Binder, M. and Bröck, S. (2006). On the relation between investment and economic growth: New cross-country empirical evidence. Mimeo, Goethe University Frankfurt. 
Blanchard, O. and Giavazzi, F. (2003). Macroeconomic Effects of Regulation and Deregulation in Goods and Labor Markets. Quarterly Journal of Economics, 118(3):879-907.

Buch, C. M., Monti, P., and Toubal, F. (2008). Trade's impact on the labor share: Evidence from german and italian regions. IAW Discussion Papers 46, Institut für Angewandte Wirtschaftsforschung (IAW).

Checchi, D. and Garcia-Peñalosa, C. (2008). Labour market institutions and income inequality. Economic Policy, 23(56):601-649.

Gollin, D. (2002). Getting income shares right. Journal of Political Economy, 110(2):458474.

Guscina, A. (2006). Effects of globalization on labor's share in national income. IMF Working Paper, 06/294.

Harrison, A. (2002). Has Globalization Eroded Labor's Share? Evidence from CrossCountry Data. manuscript UC Berkeley.

Hutchinson, J. and Persyn, D. (2009). Globalisation, concentration and footloose firms: in search of the main cause of the declining labour share. LICOS Discussion Paper Series, $(229 / 2009)$.

Jaumotte, F. and Tytell, I. (2007). How Has the Globalization of Labor Affected the Labor Income Share in Advanced Countries? IMF Working Paper, 07/298.

Pesaran, M., Shin, Y., and Smith, R. (1999). Pooled Mean Group Estimation of Dynamic Heterogeneous Panels. Journal of the American Statistical Association, 94(446):621622 .

Pesaran, M. H. (2006). Estimation and inference in large heterogeneous panels with a multifactor error structure. Econometrica, 74(4):967-1012.

Pesaran, M. H. and Smith, R. (1995). Estimating long-run relationships from dynamic heterogeneous panels. Journal of Econometrics, 68(1):79-113.

Visser, J. (2009). The ICTWSS database: Database on institutional characteristics of trade unions, wage setting, state intervention and social pacts in 34 countries between 1960 and 2007. 